\title{
Prognostic Value of Cardiac Magnetic Resonance Imaging for Idiopathic Pulmonary Arterial Hypertension Before Initiating Intravenous Prostacyclin Therapy
}

\author{
Yoshitake Yamada, MD; Shigeo Okuda, MD; Masaharu Kataoka, MD; Akihiro Tanimoto, MD; \\ Yuichi Tamura, MD; Takayuki Abe, PhD; Tomonori Okamura, MD; \\ Keiichi Fukuda, MD; Toru Satoh, MD; Sachio Kuribayashi, MD
}

Background: Because few have reported the prognostic significance of cardiac magnetic resonance imaging (CMR) for idiopathic pulmonary arterial hypertension (IPAH), in this study we evaluated the value of CMR measurements as a prognostic predictor of IPAH before starting intravenous prostacyclin therapy.

\begin{abstract}
Methods and Results: A total of 121 consecutive CMR studies for evaluating right ventricular (RV) function were reviewed. Forty-one patients were diagnosed with IPAH and served as the study group. Factors, such as age, sex, New York Heart Association functional class (NYHAFC), 6-min walk test, plasma brain natriuretic peptide level, serum uric acid level and CMR measurements were analyzed as predictors of first hospitalization and death. The mean follow-up period was $1,350 \pm 769$ days. Nine patients were hospitalized because of heart failure, and 4 patients died from cardiopulmonary causes. The univariate analyses suggested that the left ventricular (LV) mass index, the left and right ventricular end-diastolic volume indices (LVEDVI, RVEDVI), the LV and RV end-systolic volume indices (LVESVI, RVESVI) and NYHAFC predicted the risk for hospitalization and that RVEDVI, RVESVI and NYHAFC predicted mortality. The multivariate analyses suggested that RVEDVI and NYHAFC are independent predictors of both hospitalization and mortality. The effects of RVEDVI and NYHAFC on hospitalization were not substantially affected by the concomitant medication.
\end{abstract}

Conclusions: In IPAH patients, the RVEDVI predicts both hospitalization for right heart failure and mortality before initiating intravenous prostacyclin therapy. (Circ J 2012; 76: 1737-1743)

Key Words: Clinical outcome; Idiopathic pulmonary arterial hypertension; Magnetic resonance imaging

$\mathbf{I}$ diopathic pulmonary arterial hypertension (IPAH) is a lifethreatening chronic disorder that affects the pulmonary circulation and has an unknown etiology. Elevated pressure and resistance in the pulmonary vessels lead to progressive right heart failure, which results in functional limitations and ultimately the death of most patients. ${ }^{1-3}$ The prognosis is poor; without specific treatment, the 1-, 3- and 5- year survival rates are 68,48 and $34 \%$, respectively. ${ }^{4}$ Thus, monitoring right ventricular (RV) function is of great importance. Cardiac magnetic resonance imaging (CMR) is a noninvasive, 3-dimensional tomographic technique that enables visualization of the detailed morphology of the heart and accurate measurement of the RV volume, myocardial mass and transvalvular flow. ${ }^{5-8}$ It can also determine whether impaired RV diastolic function results from pulmonary hypertension. However, few studies have reported the prognostic significance of CMR measurements. ${ }^{9,10}$ Furthermore, to the best of our knowledge, the association between hospitalization for heart failure because of IPAH and CMR results has not been discussed in the literature. The purpose of this historical cohort study was to evaluate the value of CMR measurements as a prognostic predictor of IPAH before starting intravenous prostacyclin therapy.

\section{Editorial p 1595}

\section{Methods}

\section{Patients}

Our hospital is a pulmonary hypertension referral center in Japan. We performed a retrospective review of CMR results

Received October 26, 2011; revised manuscript received March 1, 2012; accepted March 13, 2012; released online April 12, 2012 Time for primary review: 19 days

Department of Diagnostic Radiology (Y.Y., S.O., A.T., S.K.), Division of Cardiology, Department of Medicine (M.K., Y.T., K.F.), Center for Clinical Research (T.A.), Department of Preventive Medicine and Public Health (T.O.), Keio University School of Medicine, Tokyo; and Second Department of Internal Medicine, Kyorin University School of Medicine, Tokyo (M.K., T.S.), Japan

Mailing address: Shigeo Okuda, MD, Department of Diagnostic Radiology, Keio University School of Medicine, 35 Shinanomachi, Shinjukuku, Tokyo 160-8582, Japan. E-mail: okuda@rad.med.keio.ac.jp

ISSN-1346-9843 doi:10.1253/circj.CJ-11-1237

All rights are reserved to the Japanese Circulation Society. For permissions, please e-mail: cj@j-circ.or.jp 


\begin{tabular}{|c|c|}
\hline $\begin{array}{c}\text { Characteristic } \\
\text { Demographic variables }\end{array}$ & Value \\
\hline Total number & 41 \\
\hline Age (years) & $39 \pm 14$ \\
\hline F/M & $29(71 \%) / 12(29 \%)$ \\
\hline \multicolumn{2}{|l|}{ CMR measurements } \\
\hline Cardiac index $\left(\mathrm{L} \cdot \mathrm{min}^{-1} \cdot \mathrm{m}^{-2}\right)$ & $2.3 \pm 0.8$ \\
\hline $\mathrm{SVI}\left(\mathrm{ml} / \mathrm{m}^{2}\right)$ & $37 \pm 14$ \\
\hline $\operatorname{RVMI}\left(\mathrm{g} / \mathrm{m}^{2}\right)$ & $39 \pm 18$ \\
\hline LVMI $\left(g / m^{2}\right)$ & $50 \pm 15$ \\
\hline RVEF (\%) & $32 \pm 12$ \\
\hline LVEF (\%) & $56 \pm 9$ \\
\hline RVEDVI (ml/m²) & $123 \pm 43$ \\
\hline RVESVI (ml/m²) & $86 \pm 39$ \\
\hline LVEDVI $\left(\mathrm{ml} / \mathrm{m}^{2}\right)$ & $61 \pm 30$ \\
\hline LVESVI (ml/m²) & $30 \pm 15$ \\
\hline \multicolumn{2}{|l|}{ Functional status } \\
\hline NYHAFC II, III, IV & 20 (49\%), 18 (44\%), 3 (7\%) \\
\hline $6 \mathrm{MWT}(\mathrm{m})(\mathrm{n}=28)^{*}$ & $358 \pm 98$ \\
\hline \multicolumn{2}{|l|}{ Biochemical markers } \\
\hline Plasma BNP (pg/ml) & $236 \pm 331$ \\
\hline Serum uric acid (mg/dl) & $6.9 \pm 2.4$ \\
\hline Medication use & All follow-up duration/before CMR \\
\hline Intravenous prostacyclin & $14(34 \%) / 0(0 \%)$ \\
\hline Endothelin-receptor antagonists & $22(54 \%) / 9(22 \%)$ \\
\hline Sildenafil & $36(88 \%) / 18(44 \%)$ \\
\hline Calcium antagonists & $9(22 \%) / 9(22 \%)$ \\
\hline
\end{tabular}

*Of all the eligible patients, only 28 had a 6MWT within 1 week of the CMR examination without changing therapy.

CMR, cardiac magnetic resonance imaging; SVI, stroke volume index; RVMI, right ventricular (RV) mass index; LVMI, left ventricular (LV) mass index; RVEF, RV ejection fraction; LVEF, LV ejection fraction; RVEDVI, RV end-diastolic volume index; RVESVI, RV end-systolic volume index; LVEDVI, LV end-diastolic volume index; LVESVI, LV end-systolic volume index; NYHAFC, New York Heart Association functional class; 6MWT, 6-min walk test; BNP, brain natriuretic peptide.

from 122 consecutive examinations of patients who were either suspected of having pulmonary arterial hypertension (PAH) or who had been diagnosed with PAH between September 2003 and September 2010 at our institute. Of the 122 examinations, 41 patients were diagnosed with IPAH and served as the study group. The diagnosis of IPAH was based on a mean pulmonary arterial pressure (PAP) $>25 \mathrm{mmHg}$ at rest, pulmonary capillary wedge pressure (PCWP) $<15 \mathrm{mmHg}$, and an elevated pulmonary vascular resistance (PVR) in a patient with no identifiable underlying causes (such as familial $\mathrm{PAH}$, drug- or toxin-induced PAH, connective tissue disease, HIV infection, portal hypertension, congenital heart disease, schistosomiasis, chronic hemolytic anemia, pulmonary veno-occlusive disease/pulmonary capillary hemangiomatosis, pulmonary hypertension owing to lung disease/hypoxia, chronic thromboembolic pulmonary hypertension or pulmonary hypertension with unclear multifactorial mechanisms). ${ }^{11,12}$

To prevent the potential risk of damaging the intravenous prostacyclin equipment in the magnetic resonance imaging (MRI) scanner rooms, CMR was not performed for patients who had started prostacyclin treatment. Accordingly, all of the IPAH patients in this study were examined before starting intravenous prostacyclin therapy. Each patient's status was

\begin{tabular}{|lc|}
\hline \multicolumn{2}{|c|}{ Table 2. Right Heart Catheterization Measurements } \\
Characteristic & Value \\
Mean PAP $(\mathrm{mmHg})$ & $51 \pm 14$ \\
Systolic PAP $(\mathrm{mmHg})$ & $80 \pm 22$ \\
Diastolic PAP $(\mathrm{mmHg})$ & $31 \pm 11$ \\
Mean right atrial pressure $(\mathrm{mmHg})$ & $6.8 \pm 4.0$ \\
PVR index (dyne s. $\left.\mathrm{cm}^{-5} \cdot \mathrm{m}^{-2}\right)$ & $737 \pm 504$ \\
Cardiac index $\left(\mathrm{L} \cdot \mathrm{min}^{-1} \cdot \mathrm{m}^{-2}\right)$ & $2.2 \pm 0.7$ \\
SVI $\left(\mathrm{ml} / \mathrm{m}^{2}\right)$ & $33 \pm 12$ \\
Heart rate (beats/min) & $72 \pm 13$ \\
Mixed venous $\mathrm{O}_{2}$ saturation $(\%)$ & $64 \pm 8$ \\
\hline
\end{tabular}

PAP, pulmonary artery pressure; PVR, pulmonary vascular resistance; SVI, stroke volume index.

scored according to their New York Heart Association functional class (NYHAFC) at the time of the CMR examination. According to clinical guidelines, patients with a positive acute vasodilator challenge during right heart catheterization were treated with calcium antagonists; ${ }^{13} 9$ patients $(22 \%)$ had been treated with an endothelin-receptor antagonist, 18 (54\%) had been treated with sildenafil, and $9(22 \%)$ had been treated with calcium antagonists before the CMR assessment. The study protocol was approved by the institutional review board.

\section{Endpoint Determination}

The follow-up data were retrospectively collected from medical charts, and the end of data collection was March 31, 2011. The following endpoints were used in this historical cohort study: (1) the date of the first hospitalization for right heart failure; (2) the date of the last clinical visit; (3) death; and (4) March 31, 2011. Clinical follow-up visits were performed at regular intervals (1-3 months) at the outpatient clinic.

\section{CMR Imaging}

The CMR scans were obtained using a 1.5-Tesla clinical scanner (Signa TwinSpeed, GE Healthcare, Milwaukee, WI, USA). For the RV volume measurements, contiguous transverse images were acquired through the entire RV using a 2D cine, steady-state, free-precession technique with prospective ECG gating. Each cross-sectional image was obtained while the patient held a single breath. Each cross-sectional image used the following parameters: repetition time $=3.2 \mathrm{~ms}$, echo time $=$ $1.6 \mathrm{~ms}$, flip angle $=45^{\circ}$, bandwidth $=125 \mathrm{kHz}$, field of view $=350 \times$ $350 \mathrm{~mm}^{2}$, matrix size $=224 \times 192$, slice thickness $=10 \mathrm{~mm}$ without a gap and 20 phases during 1 cardiac cycle. The in-plane spatial resolution was $1.6 \times 1.8 \mathrm{~mm}^{2}$. The CMR examination time was approximately $30 \mathrm{~min}$ and included short-axis images of the left ventricle (LV) to evaluate LV function after obtaining transverse images of the RV. The CMR functional parameters were calculated on a workstation (Advantage Workstation, GE Healthcare). The endocardial borders of all of the images at end-diastole and end-systole were manually traced by a radiologist with 10 years of experience with CMR. The end-diastolic volume, end-systolic volume, and ejection fraction (EF) were automatically calculated using Simpson's rule with commercially available analysis software (Mass Analysis Plus version 4.0, Medis, Leiden, the Netherlands). The incorporation of the trabeculae carneae into the RV volume followed the rules that are generally used in ultrasound methods. Fewer than $15 \mathrm{~min}$ were required for the RV volume measurement. The cardiac output was determined by multiplying the stroke volume by the heart rate. The measures were indexed by 


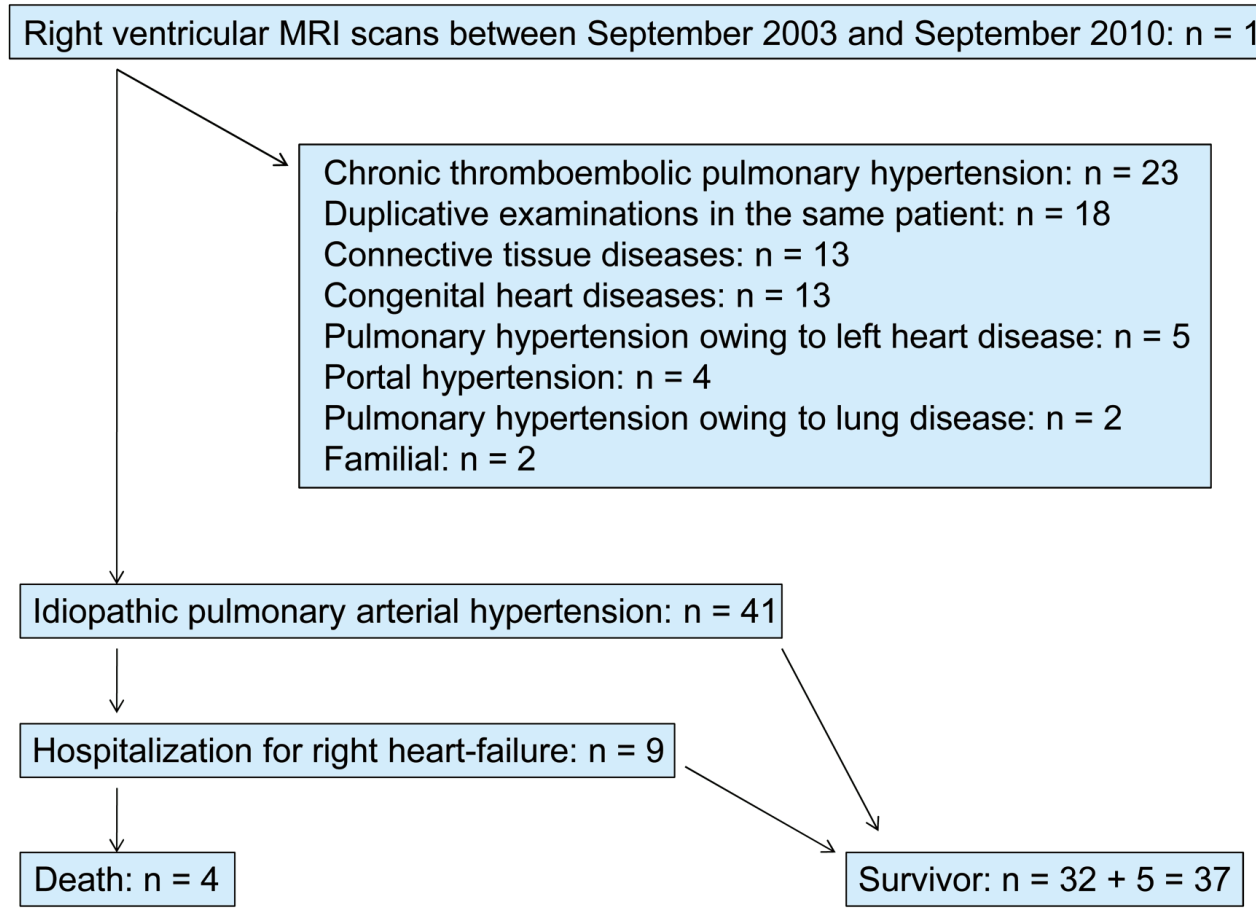

Figure. Study profile.

correcting for the patient's body surface area. The RVEF and LVEF were determined by dividing the systolic volume by the right and left end-diastolic volumes, respectively.

\section{Right Heart Catheterization}

A diagnostic right-heart catheterization was performed using a balloon-tipped, flow-directed 7F Swan-Ganz catheter. The patient was stable, lay supine, and breathed room air. The PAP, right atrial pressure, PCWP, cardiac output, PVR index and mixed venous oxygen saturation were measured. Blood was sampled with the catheter positioned inside the main pulmonary artery. The arterial oxygen saturation was measured using blood sampled from the radial or femoral artery. The cardiac output was assessed using the Fick method, and the PVR was calculated using the following formula: (mPAP-PCWP)/ cardiac output. All of the eligible patients had right-heart catheterization examinations within 6 months of their CMR examinations.

\section{Statistical Analysis}

All data are expressed as the mean \pm standard deviation (SD). The hazard ratios of the factors potentially associated with a first hospitalization (primary endpoint) or death after hospitalization (secondary endpoint), such as age, sex, NYHAFC, biochemical markers and the CMR measures, were calculated using a Cox proportional-hazards model. First, the hazard ratio and $95 \%$ confidence interval (CI) for each factor were estimated using a univariate model. The following variables were tested: age, sex, the NYHAFC, the distance in a 6-min walk test (6MWT), the plasma brain natriuretic peptide (BNP) level, ${ }^{14}$ the serum uric acid level, ${ }^{15}$ the cardiac index, the stroke volume index (SVI), the RV mass index (RVMI), the LV mass index (LVMI), RVEF, LVEF, the RV end-systolic volume index (RVESVI), the RV end-diastolic volume index (RVEDVI), the LV end-systolic volume index (LVESVI) and the LV enddiastolic volume index (LVEDVI). Catheterization was not performed on the same day as the CMR examination, so the right heart catheterization variables were not tested. To examine the robustness of the univariate results, multivariate Cox regression analyses with step-wise variable selection were performed. A multivariate Cox model with time-dependent covariates was also used to evaluate the effects of any concomitant medications during the follow-up period.

We added exploratory analyses with respect to the endpoint of clinical worsening, including all clinical events (additional therapies in response to clinical worsening, hospitalization and death) with a univariate Cox regression model.

All of the confidence intervals were estimated at the $95 \%$ confidence level, and significance was set at a $\mathrm{P}<0.05$ (2-tailed). All of the data were analyzed using a commercially available software program (SAS version 9.1, Cary, NC, USA).

\section{Results}

\section{Patients' Characteristics}

The patients' demographic and baseline CMR data are summarized in Table 1 . The right heart catheterization measurements collected within 6 months of each CMR examination are also shown in Table 2. Over a mean follow-up period of 1,350 \pm 769 (range: 196-2,654) days, 9 of the 41 patients were hospitalized for right heart failure; 4 of the 9 hospitalized patients died and none died from non-cardiopulmonary causes (Figure). In 29 patients (71\%), the medical therapy was changed because of clinical worsening. Intravenous prostacyclin, endothelin-receptor antagonists and sildenafil were added in 14, 13 and 18 patients, respectively (Table 1 ). All the patients were 


\begin{tabular}{|c|c|c|c|c|c|c|c|c|}
\hline & \multicolumn{4}{|c|}{ Hospitalization for right HF } & \multicolumn{4}{|c|}{ Mortality } \\
\hline & \multirow{2}{*}{ HR } & \multicolumn{2}{|c|}{$95 \% \mathrm{Cl}$} & \multirow{2}{*}{$P$ value } & \multirow{2}{*}{ HR } & \multicolumn{2}{|c|}{$95 \% \mathrm{Cl}$} & \multirow{2}{*}{$P$ value } \\
\hline & & Lower & Upper & & & Lower & Upper & \\
\hline \multicolumn{9}{|l|}{ Demographic variables } \\
\hline Age (year) & 1.01 & 0.97 & 1.05 & 0.716 & 1.04 & 0.98 & 1.12 & 0.193 \\
\hline $\operatorname{Sex}(M / F)$ & 2.00 & 0.54 & 7.48 & 0.301 & 2.36 & 0.33 & 16.73 & 0.392 \\
\hline \multicolumn{9}{|l|}{ CMR measurements } \\
\hline Cardiac index $\left(\mathrm{L} \cdot \mathrm{min}^{-1} \cdot \mathrm{m}^{-2}\right)$ & 0.81 & 0.33 & 1.98 & 0.645 & 0.46 & 0.09 & 2.43 & 0.358 \\
\hline $\mathrm{SVI}\left(\mathrm{ml} / \mathrm{m}^{2}\right)$ & 1.01 & 0.97 & 1.05 & 0.645 & 0.98 & 0.91 & 1.06 & 0.681 \\
\hline RVMI (g/m²) & 0.96 & 0.88 & 1.06 & 0.444 & 0.96 & 0.88 & 1.05 & 0.401 \\
\hline LVMI $\left(\mathrm{g} / \mathrm{m}^{2}\right)$ & 1.07 & 1.02 & 1.12 & $0.008^{*}$ & 1.03 & 0.97 & 1.10 & 0.386 \\
\hline RVEF (\%) & 0.97 & 0.92 & 1.03 & 0.351 & 0.96 & 0.87 & 1.05 & 0.369 \\
\hline LVEF (\%) & 0.95 & 0.88 & 1.02 & 0.175 & 0.97 & 0.86 & 1.08 & 0.527 \\
\hline RVEDVI (ml/m²) & 1.02 & 1.00 & 1.03 & $0.012^{*}$ & 1.02 & 1.00 & 1.04 & $0.028^{*}$ \\
\hline RVESVI (ml/m²) & 1.02 & 1.00 & 1.03 & $0.014^{*}$ & 1.03 & 1.00 & 1.05 & $0.021^{*}$ \\
\hline LVEDVI $\left(\mathrm{ml} / \mathrm{m}^{2}\right)$ & 1.03 & 1.00 & 1.05 & $0.019^{\star}$ & 1.00 & 0.95 & 1.04 & 0.932 \\
\hline LVESVI (ml/m²) & 1.04 & 1.00 & 1.07 & $0.027^{\star}$ & 1.00 & 0.92 & 1.08 & 0.907 \\
\hline \multicolumn{9}{|l|}{ Functional status } \\
\hline NYHAFC & 4.61 & 1.69 & 12.55 & $0.003^{*}$ & 6.23 & 1.29 & 30.13 & $0.023^{\star}$ \\
\hline 6MWT (m) & 1.00 & 0.99 & 1.01 & 0.467 & 1.00 & 0.98 & 1.02 & 0.799 \\
\hline \multicolumn{9}{|l|}{ Biochemical markers } \\
\hline Plasma BNP (pg/ml) & 1.00 & 1.00 & 1.00 & 0.129 & 1.00 & 1.00 & 1.00 & 0.197 \\
\hline Serum uric acid $(\mathrm{mg} / \mathrm{dl})$ & 1.25 & 0.98 & 1.59 & 0.075 & 1.38 & 0.95 & 2.00 & 0.087 \\
\hline
\end{tabular}

${ }^{*} \mathrm{P}<0.05$.

$\mathrm{HF}$, heart failure; $\mathrm{HR}$, hazard ratio; $\mathrm{Cl}$, confidence interval. Other abbreviations as in Table 1.

\begin{tabular}{|c|c|c|c|c|}
\hline & \multicolumn{4}{|c|}{ Hospitalization for right HF } \\
\hline & \multirow{2}{*}{ HR } & \multicolumn{2}{|c|}{$95 \% \mathrm{Cl}$} & \multirow{2}{*}{$P$ value } \\
\hline & & Lower & Upper & \\
\hline RVEDVI $\left(\mathrm{ml} / \mathrm{m}^{2}\right)$ & 1.02 & 1.00 & 1.03 & $0.010^{*}$ \\
\hline LVEDVI $\left(\mathrm{ml} / \mathrm{m}^{2}\right)$ & 1.02 & 1.00 & 1.05 & 0.052 \\
\hline NYHAFC & 7.66 & 2.05 & 28.61 & $0.002^{*}$ \\
\hline
\end{tabular}

${ }^{*} \mathrm{P}<0.05$.

Abbreviations as in Tables 1,3.

\begin{tabular}{|c|c|c|c|c|}
\hline & \multicolumn{4}{|c|}{ Mortality } \\
\hline & \multirow{2}{*}{ HR } & \multicolumn{2}{|c|}{$95 \% \mathrm{Cl}$} & \multirow{2}{*}{$P$ value } \\
\hline & & Lower & Upper & \\
\hline RVEDVI $\left(\mathrm{ml} / \mathrm{m}^{2}\right)$ & 1.03 & 1.00 & 1.05 & $0.020^{*}$ \\
\hline NYHAFC & 21.85 & 1.46 & 328.14 & $0.023^{*}$ \\
\hline
\end{tabular}

${ }^{*} \mathrm{P}<0.05$.

Abbreviations as in Tables 1,3.

\begin{tabular}{|c|c|c|c|c|c|c|c|c|}
\hline \multirow{3}{*}{ Therapy } & \multicolumn{4}{|c|}{ Hospitalization for right HF } & \multicolumn{4}{|c|}{ Mortality } \\
\hline & \multirow{2}{*}{ HR } & \multicolumn{2}{|c|}{$95 \% \mathrm{Cl}$} & \multirow{2}{*}{$P$ value } & \multirow{2}{*}{ HR } & \multicolumn{2}{|c|}{$95 \% \mathrm{Cl}$} & \multirow{2}{*}{$P$ value } \\
\hline & & Lower & Upper & & & Lower & Upper & \\
\hline Intravenous prostacyclin & 2.87 & 0.77 & 10.72 & 0.117 & 2.09 & 0.29 & 14.90 & 0.461 \\
\hline Endothelin-receptor antagonists & 0.52 & 0.14 & 1.96 & 0.334 & 0.23 & 0.02 & 2.24 & 0.207 \\
\hline Sildenafil ${ }^{\dagger}$ & - & - & - & $(0.994)$ & - & - & - & $(0.996)$ \\
\hline Calcium antagonists & 1.02 & 0.21 & 4.92 & 0.981 & 1.18 & 0.12 & 11.36 & 0.885 \\
\hline
\end{tabular}

${ }^{\dagger}$ All hospitalized or deceased patients were treated with sidenafil. Abbreviations as in Table 3.

treated with oral anticoagulants.

\section{Predictors of Hospitalization for Right Heart Failure or Mortality}

The univariate Cox regression analyses suggested that LVMI, LVEDVI, LVESVI, RVEDVI, RVESVI and NYHAFC were associated with the time to hospitalization (primary endpoint) in the IPAH patients and that RVEDVI, RVESVI and NYHAFC were associated with the time to death (secondary endpoint) (Table 3). The RVEDVI was closely related to the RVESVI, and the LVEDVI was closely related to the LVESVI and LVMI; therefore, multivariate Cox regression analyses were performed using RVEDVI, LVEDVI and NYHAFC as predictors of the hazard of hospitalization and RVEDVI and 


\begin{tabular}{|c|c|c|c|c|}
\hline \multirow{3}{*}{ Therapy/Variable } & \multicolumn{4}{|c|}{ Hospitalization for right HF } \\
\hline & \multirow{2}{*}{ HR } & \multicolumn{2}{|c|}{$95 \% \mathrm{Cl}$} & \multirow{2}{*}{$P$ value } \\
\hline & & Lower & Upper & \\
\hline \multicolumn{5}{|l|}{ Intravenous prostacyclin } \\
\hline RVEDVI $\left(\mathrm{ml} / \mathrm{m}^{2}\right)$ & 1.02 & 1.01 & 1.04 & $0.008^{*}$ \\
\hline NYHAFC & 5.02 & 1.17 & 21.54 & $0.030^{*}$ \\
\hline Time-dependent covariate (intravenous prostacyclin) & 4.60 & 0.96 & 21.92 & 0.055 \\
\hline \multicolumn{5}{|l|}{ Endothelin-receptor antagonists } \\
\hline RVEDVI $\left(\mathrm{ml} / \mathrm{m}^{2}\right)$ & 1.02 & 1.01 & 1.03 & $0.005^{*}$ \\
\hline NYHAFC & 9.24 & 2.16 & 39.43 & $0.003^{*}$ \\
\hline Time-dependent covariate (endothelin-receptor antagonists) & 2.47 & 0.47 & 12.98 & 0.286 \\
\hline \multicolumn{5}{|l|}{ Sildenafil ${ }^{\dagger}$} \\
\hline RVEDVI $\left(\mathrm{ml} / \mathrm{m}^{2}\right)$ & 1.02 & 1.00 & 1.03 & $0.009^{*}$ \\
\hline NYHAFC & 5.21 & 1.51 & 18.02 & $0.009^{*}$ \\
\hline Time-dependent covariate (sildenafil) ${ }^{\dagger}$ & $--^{\dagger}$ & $-\dagger$ & $-\dagger$ & $(0.995)^{\dagger}$ \\
\hline \multicolumn{5}{|l|}{ Calcium antagonists } \\
\hline RVEDVI $\left(\mathrm{ml} / \mathrm{m}^{2}\right)$ & 1.02 & 1.00 & 1.03 & $0.009^{*}$ \\
\hline NYHAFC & 8.01 & 2.11 & 30.49 & $0.002^{*}$ \\
\hline Time-dependent covariate (calcium antagonists) & 0.52 & 0.10 & 2.70 & 0.438 \\
\hline
\end{tabular}

${ }^{*} P<0.05$. ${ }^{\dagger}$ Because of a high percentage of patients treated with sildenafil $(88 \%)$, it was impossible to evaluate the effect of sildenafil by means of multivariate Cox model with time-dependent covariate.

Abbreviations as in Tables 1,3.

NYHAFC as predictors of mortality. The multivariate analyses using step-wise variable selection showed that the RVEDVI and NYHAFC were independent predictors of the hazards of both hospitalization and mortality (Tables 4,5).

There was no significant relationship between the endpoints and the type of therapy (ie, intravenous prostacyclin, endothelin-receptor antagonist, sildenafil and calcium antagonists; Table 6). Furthermore, the effects of RVEDVI and NYHAFC on hospitalization were not substantially changed in a timedependent Cox model with additional adjustments for any concomitant medications during the follow-up period (Table 7). However, because of the large percentage of patients treated with sildenafil (88\%), it was impossible to evaluate the effects of sildenafil using this statistical model.

\section{Results of Exploratory Data Analyses}

Clinical worsening, including all clinical events (additional therapies in response to clinical worsening, hospitalization and death), occurred in 32 of 41 patients. In the univariate Cox regression model, there was no significant association between clinical worsening and any variables including age, sex, NYHAFC, 6MWT, BNP level, serum uric acid level and CMR measurements.

\section{Discussion}

In this study, we investigated the prognostic significance of CMR measurements in patients with IPAH before initiating intravenous prostacyclin therapy. We found that increased RVEDVI and NYHAFC were associated with both hospitalization for right heart failure and mortality.

In our study, we only focused on patients with IPAH. Some previous studies have included multiple types of PAH patients (category 1 of the Venice or Dana Point classification ${ }^{11}$ ) in their cohorts and subsequent analyses. Although this approach may be appropriate for some therapeutic studies, ${ }^{16}$ the validity of this practice is questionable when evaluating prognostic fac- tors. ${ }^{17}$ It is well known that survival curves are not comparable across all subgroups of category $1 \mathrm{PAH},{ }^{18}$ and therefore it should not be assumed that the prognostic variables will be identical in the various populations.

Compared with other diagnostic tools, the advantages of CMR are its noninvasiveness, non-ionizing safety, excellent spatial and temporal resolution, and repeatability. CMR is more reproducible than echocardiography when measuring RV function. ${ }^{19}$ There have been few previous studies that have addressed the relationships between CMR measures and clinical outcomes in IPAH patients. Previous studies have demonstrated that an increased RVEDVI, a large right atrium, and a low RVSVI are associated with a poor prognosis., ${ }^{920,21}$ However, to the best of our knowledge, the associations between hospitalization for heart failure because of IPAH and the CMR results have not yet been reported. We found that the RVEDVI and RVESVI were associated with both hospitalization for right heart failure and mortality. This finding is clinically important because CMR provides a direct RV parameter for predicting early RV failure (before the initiation of intravenous prostacyclin therapy). Measures of increased RVEDVI and RVESVI could be used to predict treatment failure and, thus, could offer an opportunity to change the patient's treatment or add the patient to the transplant list before RV failure leads to death. ${ }^{9}$ It is well known that the RV compensates for increased afterload via enlargement and hypertrophy. At some point, the $\mathrm{RV}$ is unable to further adapt to the increased afterload, and $\mathrm{RV}$ failure occurs, leading to hospitalization for heart failure or imminent death.

A previous study enrolling 64 IPAH patients revealed a significantly better survival in the patients with RVEDVI $<84 \mathrm{ml} / \mathrm{m}^{2}$ than in those with RVEDVI $\geq 84 \mathrm{ml} / \mathrm{m}^{2}{ }^{9}$ In our post hoc analysis by means of a Cox regression, treating the RVEDVI as a binary variable, no event was observed in patients with RVEDVI $<84 \mathrm{ml} / \mathrm{m}^{2}$ during a longer mean follow-up period ( $32 \pm 16$ vs. $45 \pm 26$ months), which is consistent with the previous finding; however, we did not observe enough events in the 
patients with RVEDVI $\geq 84 \mathrm{ml} / \mathrm{m}^{2}$ to establish a significant difference between the groups (Figure S1). Thus, in the statistical analyses presented here, we treated each factor (eg, RVEDVI) as a continuous variable to avoid the loss of information associated with creating binary variables.

In our study, the NYHAFC was an independent predictor of both hospitalization and mortality. Previous studies have reported that this classification is a prognostic factor for mortality in IPAH patients. ${ }^{22-24}$ Sitbon et al have reported that the survival of primary pulmonary hypertension patients treated with intravenous prostacyclin is associated with the NYHAFC at baseline, ${ }^{23}$ and our results are consistent with that.

Our univariate analyses also found that LVEDVI, LVESVI and LVMI were associated with hospitalization; however, these 3 parameters were not associated with mortality. The reason for the discrepancy in P-values between hospitalization and death events may have been related to the difference in the numbers of events; that is, the statistical power of the death-event data (4 events) is lower than that of the hospitalization-event data (9 events). In the multivariate model, these 3 parameters did not predict our patients' prognoses, which may have been related to the strong effect of the RVEDVI on the severity of the IPAH. Additional large-scale studies are warranted.

The exploratory analyses showed no significant association between clinical worsening (all clinical events, including additional therapies, hospitalization and death) and any variables in our study. One explanation is that too many events (32 out of 41 patients) may have resulted in a low statistical power in the exploratory analyses of our patient population. Furthermore, hospitalization and death were more clinically relevant than the total of all clinical events (new additional therapies, hospitalization and death) and would have a higher power to detect associations between the MRI findings and the patients' prognoses in this study.

\section{Study Limitations}

First, this was an observational study with a cohort limited to a 45-month period. Second, our single measurement of the CMR parameters at the time of study entry and our inability to evaluate the longitudinal trends in these parameters may have led to an underestimation of the relationships between the CMR measures and our endpoints because of regression-dilution bias. Third, because our study had an observational design, the IPAH therapies were not controlled. However, there was no significant relationship between the endpoints and the medications used. Furthermore, the effects of RVEDVI and NYHAFC on hospitalization were consistent when the concomitant medications were included as time-dependent covariates. Finally, our data were obtained from a single center and should be evaluated in other centers.

\section{Conclusions}

In IPAH patients, the RVEDVI obtained from CMR measurements predicts both hospitalization for right heart failure and mortality before initiating intravenous prostacyclin therapy.

\section{Acknowledgment}

The authors acknowledge Yohei Ohno for important suggestions.

\section{Disclosures}

Funding/Support: None.

\section{References}

1. McLaughlin VV, Archer SL, Badesch DB, Barst RJ, Farber HW, Lindner JR, et al. ACCF/AHA 2009 expert consensus document on pulmonary hypertension a report of the American College of Cardiology Foundation Task Force on Expert Consensus Documents and the American Heart Association developed in collaboration with the American College of Chest Physicians; American Thoracic Society, Inc.; and the Pulmonary Hypertension Association. J Am Coll Cardiol 2009; 53: 1573-1619.

2. Badesch DB, Abman SH, Simonneau G, Rubin LJ, McLaughlin VV. Medical therapy for pulmonary arterial hypertension: Updated ACCP evidence-based clinical practice guidelines. Chest 2007; 131: 1917 1928.

3. Fukumoto Y, Shimokawa H. Recent progress in the management of pulmonary hypertension. Circ J 2011; 75: 1801-1810.

4. D'Alonzo GE, Barst RJ, Ayres SM, Bergofsky EH, Brundage BH, Detre KM, et al. Survival in patients with primary pulmonary hypertension: Results from a national prospective registry. Ann Intern Med 1991; 115: 343-349.

5. Lang IM, Plank C, Sadushi-Kolici R, Jakowitsch J, Klepetko W, Maurer G. Imaging in pulmonary hypertension. JACC Cardiovasc Imaging 2010; 3: 1287-1295.

6. Marrone G, Mamone G, Luca A, Vitulo P, Bertani A, Pilato M, et al. The role of $1.5 \mathrm{~T}$ cardiac MRI in the diagnosis, prognosis and management of pulmonary arterial hypertension. Int J Cardiovasc Imaging 2010; 26: 665-681.

7. Benza R, Biederman R, Murali S, Gupta H. Role of cardiac magnetic resonance imaging in the management of patients with pulmonary arterial hypertension. J Am Coll Cardiol 2008; 52: 1683-1692.

8. Kang KW, Chang HJ, Kim YJ, Choi BW, Lee HS, Yang WI, et al. Cardiac magnetic resonance imaging-derived pulmonary artery distensibility index correlates with pulmonary artery stiffness and predicts functional capacity in patients with pulmonary arterial hypertension. Circ J 2011; 75: 2244-2251.

9. van Wolferen SA, Marcus JT, Boonstra A, Marques KM, Bronzwaer JG, Spreeuwenberg MD, et al. Prognostic value of right ventricular mass, volume, and function in idiopathic pulmonary arterial hypertension. Eur Heart J 2007; 28: 1250- 1257.

10. Gan CT, Lankhaar JW, Westerhof N, Marcus JT, Becker A, Twisk JW, et al. Noninvasively assessed pulmonary artery stiffness predicts mortality in pulmonary arterial hypertension. Chest 2007; 132: $1906-$ 1912.

11. Simonneau G, Robbins IM, Beghetti M, Channick RN, Delcroix M, Denton $\mathrm{CP}$, et al. Updated clinical classification of pulmonary hypertension. J Am Coll Cardiol 2009; 54: S43-S54.

12. Badesch DB, Champion HC, Sanchez MA, Hoeper MM, Loyd JE, Manes A, et al. Diagnosis and assessment of pulmonary arterial hypertension. J Am Coll Cardiol 2009; 54: S55-S66.

13. Galie N, Torbicki A, Barst R, Dartevelle P, Haworth S, Higenbottam $\mathrm{T}$, et al. Guidelines on diagnosis and treatment of pulmonary arterial hypertension: The Task Force on Diagnosis and Treatment of Pulmonary Arterial Hypertension of the European Society of Cardiology. Eur Heart J 2004; 25: 2243-2278.

14. Nagaya N, Nishikimi T, Uematsu M, Satoh T, Kyotani S, Sakamaki $\mathrm{F}$, et al. Plasma brain natriuretic peptide as a prognostic indicator in patients with primary pulmonary hypertension. Circulation 2000; 102: $865-870$.

15. Nagaya N, Uematsu M, Satoh T, Kyotani S, Sakamaki F, Nakanishi $\mathrm{N}$, et al. Serum uric acid levels correlate with the severity and the mortality of primary pulmonary hypertension. Am J Respir Crit Care Med 1999; 160: 487-492.

16. Satoh T, Saji T, Watanabe H, Ogawa S, Takehara K, Tanabe N, et al. A phase III, multicenter, collaborative, open-label clinical trial of sildenafil in Japanese patients with pulmonary arterial hypertension. Circ J 2011; 75: 677-682.

17. Swiston JR, Johnson SR, Granton JT. Factors that prognosticate mortality in idiopathic pulmonary arterial hypertension: A systematic review of the literature. Respir Med 2010; 104: 1588-1607.

18. McLaughlin VV, Presberg KW, Doyle RL, Abman SH, McCrory DC, Fortin T, et al. Prognosis of pulmonary arterial hypertension: ACCP evidence-based clinical practice guidelines. Chest 2004; 126: 78S-92S

19. McLure LE, Peacock AJ. Imaging of the heart in pulmonary hypertension. Int J Clin Pract Suppl 2007; 61(Suppl156): 15-26.

20. Gan CT, Holverda S, Marcus JT, Paulus WJ, Marques KM, Bronzwaer JG, et al. Right ventricular diastolic dysfunction and the acute effects of sildenafil in pulmonary hypertension patients. Chest 2007; 132: $11-17$.

21. Kovacs G, Reiter G, Reiter U, Rienmuller R, Peacock A, Olschewski 
$\mathrm{H}$. The emerging role of magnetic resonance imaging in the diagnosis and management of pulmonary hypertension. Respiration 2008; 76: $458-470$.

22. Barst RJ, Galie N, Naeije R, Simonneau G, Jeffs R, Arneson C, et al. Long-term outcome in pulmonary arterial hypertension patients treated with subcutaneous treprostinil. Eur Respir J 2006; 28: 1195 1203.

23. Sitbon O, Humbert M, Nunes H, Parent F, Garcia G, Herve P, et al. Long-term intravenous epoprostenol infusion in primary pulmonary hypertension: Prognostic factors and survival. J Am Coll Cardiol 2002; 40: 780-788.

24. Raymond RJ, Hinderliter AL, Willis PW, Ralph D, Caldwell EJ,
Williams W, et al. Echocardiographic predictors of adverse outcomes in primary pulmonary hypertension. J Am Coll Cardiol 2002; 39: $1214-1219$.

\section{Supplementary Files}

Supplementary File 1

Figure S1. Kaplan-Meier plots showing survival in patients with IPAH categorized according to RVEDVI $<84 \mathrm{ml} / \mathrm{m}^{2}$ or $\geq 84 \mathrm{ml} / \mathrm{m}^{2}$.

Please find supplementary file(s);

http://dx.doi.org/10.1253/circj.CJ-11-1237 